\title{
A subpopulation of cancer stem cells identifies radiographic characteristics in glioblastoma
}

\author{
JA EUN KIM $^{1 *}$, SUNG KWON KIM ${ }^{2 *}$, JAEKYUNG SHIN ${ }^{1}$, YOUNG-BEM SE ${ }^{1}$, SEUNG HONG CHOI ${ }^{3}$, \\ SUNG-HYE PARK ${ }^{4}$, SEUNG AH CHOI ${ }^{1,5}$, JI YEOUN LEE ${ }^{6}$, JI HOON PHI ${ }^{1,5}$, \\ KYU-CHANG WANG ${ }^{1,5}$, CHUL-KEE PARK ${ }^{1}$ and SEUNG-KI KIM ${ }^{1,5}$ \\ ${ }^{1}$ Department of Neurosurgery, Seoul National University Hospital, Seoul National University College of Medicine, \\ Seoul 110-744; ${ }^{2}$ Department of Neurosurgery, Gyeongsang National University School of Medicine, \\ Gyeongsang National University Hospital, Jinju 660-702; Departments of ${ }^{3}$ Radiology and ${ }^{4}$ Pathology, \\ Seoul National University Hospital, Seoul National University College of Medicine; \\ ${ }^{5}$ Division of Pediatric Neurosurgery, Seoul National University Children's Hospital; ${ }^{6}$ Department of Anatomy, \\ Seoul National University College of Medicine, Seoul 110-744, Republic of Korea
}

Received July 14, 2015; Accepted December 9, 2016

DOI: $10.3892 / 01.2016 .5548$

\begin{abstract}
Cancer stem cells (CSCs), defined by CD133 expression, harbor heterogeneous subpopulations of cells, including endothelial progenitor cells (EPCs). This study aimed to investigate whether a subpopulation of CSCs could affect the radiographic characteristics of glioblastoma. Tissue samples from 10 patients newly diagnosed with glioblastoma were selected according to the radiographic characteristics of their tumors. The patients were divided into two groups based on preoperative magnetic resonance imaging demonstrating contrast enhancement, necrosis and infiltrative patterns: the enhancement/necrosis group $(\mathrm{E} / \mathrm{N}, \mathrm{n}=5)$ and the non-enhancement/infiltration group (NE/I, $n=5)$. Flow cytometry was used to assess the CSCs while immunohistochemistry was used to study microvessel density and the proliferation index. The $\mathrm{EPC}\left(\mathrm{CD} 34^{+} / \mathrm{CD} 133^{+}\right)$fraction in $\mathrm{CSC}$ s $\left(\mathrm{CD} 133^{+}\right)$was larger in the NE/I group. However, there was little difference in the angiogenic activity assessed using microvessel density
\end{abstract}

Correspondence to: Professor Chul-Kee Park, Department of Neurosurgery, Seoul National University Hospital, Seoul National University College of Medicine, 101 Daehak-ro, Jongno-gu, Seoul 110-744, Republic of Korea

E-mail:nsckpark@snu.ac.kr

Professor Seung-Ki Kim, Division of Pediatric Neurosurgery, Seoul National University Children's Hospital, Seoul National University College of Medicine, 101 Daehak-ro, Jongno-gu, Seoul 110-744, Republic of Korea

E-mail:nsthomas@snu.ac.kr

*Contributed equally

Key words: glioblastoma, cancer stem cell, endothelial progenitor cell, contrast enhancement, CD133, CD34 between the two groups. The proliferation index (assessed using the antibody $\mathrm{Ki}-67$ ) was higher in the E/N group and was negatively correlated with the EPC fraction. The non-EPC $\left(\mathrm{CD} 34 \% \mathrm{CD} 133^{+}\right)$fraction is a major factor responsible for radiographic characteristics of contrast enhancement, thus establishing an association between a subpopulation fraction of CSCs and radiographic characteristics in glioblastoma. Therefore, the simple non-invasive assessment of studying contrast enhancement lesions in glioblastomas may be used to estimate CSC subpopulations.

\section{Introduction}

The cell surface marker CD133 (prominin 1) has long been regarded as a classic signature of cancer stem cells (CSCs) in glioblastomas $(1,2)$. However, there has been controversy surrounding the existence of brain tumor-initiating cells lacking CD133 expression (3-7), as well as subpopulation heterogeneity in $\mathrm{CD}_{133^{+}}$cells (8). For convenience, CSCs are designated here as $\mathrm{CD}_{133^{+}}$-expressing cells of glioblastomas. Despite conflicting views concerning their origin, evidence from previous studies, including our own previous study, has revealed that the endothelial progenitor cell (EPC) subpopulation in CSCs (CD34 ${ }^{+} / \mathrm{CD} 133^{+}$cells) has angiogenic potential (9-12). Our previous study demonstrated that this proportion of the $\mathrm{CD} 34^{+} / \mathrm{CD} 133^{+} \mathrm{EPC}$ subpopulation in $\mathrm{CSCs}$ varies among different tumor types, and that EPCs are not oncogenic (9). In fact, it is the non-EPC subpopulation in CSCs (CD34 /CD133 ${ }^{+}$cells) that has oncogenic potential (9). Therefore, it is of interest to evaluate the fractions of these cell subpopulations in CSCs from individual glioblastoma patients and to predict their oncogenic and angiogenic potential.

Glioblastoma is a highly vascularized tumor. Glioma contrast enhancement detected using magnetic resonance imaging (MRI) may be due to angiogenesis, tumor cell proliferation and blood-brain barrier disruption. Numerous studies have investigated the correlation between characteristics 
identified by tumor imaging and the molecular signatures of gliomas (13-15). Thus, the finding of significant associations between molecular characteristics and specific MRI tumor features may lead to the establishment of a non-invasive method of predicting molecular signatures that aids in selecting treatment options, or even in predicting the prognosis of individual patients.

In this study, we examined the associations between subpopulation fractions of CSCs and their MRI characteristics. First, we tested whether contrast enhancement is associated with EPC fractions in glioblastoma CSCs and then investigated whether angiogenesis is influenced by EPC fractions. We observed that non-EPC fractions in CSCs are associated with the proliferation and contrast enhancement phenotype in glioblastomas.

\section{Materials and methods}

Study population. Ten patients with newly diagnosed glioblastoma were selected from the Department of Neurosurgery database (Seoul National University Hospital, Korea), according to the radiographic characteristics. Based on preoperative MRIs demonstrating contrast enhancement, necrosis and infiltrative patterns, patients were classified into two groups: the enhancement/necrosis group $(\mathrm{E} / \mathrm{N}, \mathrm{n}=5)$ and the non-enhancement/infiltration group (NE/I, n=5; Fig. 1). For the E/N group, patients were selected if they had the following MRI characteristics: a contrast-enhancing volume exceeding $50 \%$ of the entire tumor volume; the presence of necrosis; and minimal-high T2 signal intensity areas around the contrast-enhancing and necrotic portions of the tumor. For the NE/I group, patients were selected if they had the following MRI characteristics: the absence of, or only patchy $(<5 \%$ of the entire tumor volume) enhancement in the tumor; no evidence of necrosis; and an ill-defined margin of high T2 signal intensity without the classic appearance of vasogenic edema. The histological diagnosis of glioblastoma was confirmed in all cases following surgery. The general characteristics of the patients and molecular characteristics of their tumors are summarized in Table I. This study was approved by the Institutional Review Board of Seoul National University Hospital, and patient consent was obtained.

Tissue samples. Tissue samples were obtained intra-operatively. A number of tumor samples were snap-frozen in liquid nitrogen in the operating room and stored at $-80^{\circ} \mathrm{C}$ until subsequent use for fluorescence-activated cell sorting (FACS) analyses. The remaining tissue samples were fixed with formalin and embedded in paraffin (FFPE). Using the FFPE samples, a tissue microarray was built for immunohistochemistry (IHC) studies. Representative paraffin blocks were selected and mounted on slides for hematoxylin and eosin (H\&E) staining. Cores from representative areas of each tumor were marked on an H\&E-stained tissue section and an original donor block. Three 2-mm-diameter tissue cores were extracted from the marked area of each donor block. A 4- $\mu$ m-thick section was cut from each array block.

Tissue FACS. Tissue FACS was performed as previously described, with a few modifications (16). For the dissociation of frozen tumor tissues, the tissues were washed twice with sterile phosphate-buffered saline (PBS) and minced using a steel blade. The tissues were enzymatically digested by incubation with an enzyme cocktail $(100 \mathrm{U} / \mathrm{ml}$ collagenase, $0.001 \mathrm{U} / \mathrm{ml}$ DNasel and $2.4 \mathrm{U} / \mathrm{ml}$ dispase) for $1 \mathrm{~h}$ at $37^{\circ} \mathrm{C}$ and then filtered through a Falcon ${ }^{\circledR} 40 \mu \mathrm{m}$ cell strainer (cat. no. 352340; Corning Life Sciences, Corning, NY, USA) to remove any clumps or tissue debris. Red blood cells in the samples were removed by incubation with Buffer EL (cat. no. 19075, Qiagen, Valencia, CA, USA). Cells were re-suspended in Dulbecco's modified Eagle's medium (DMEM; cat. no. LM001-05; Welgene Inc., Seoul, Korea), with $10 \%$ Gibco $^{\circledR}$ fetal bovine serum (FBS; cat. no. 12483-020; Invitrogen Life Technologies, Carlsbad, CA, USA) and 1\% Gibco Antibiotic-Antimycotic (cat. no. 15240-060; Invitrogen Life Technologies), and then incubated overnight at $37^{\circ} \mathrm{C}$ in humidified atmosphere containing $5 \%$ carbon dioxide.

Specimens were washed twice with FACS buffer (PBS containing 2\% Gibco FBS (cat. no. 12483-020; Invitrogen Life Technologies) and stained with pre-conjugated monoclonal antibodies with allophycocyanin (APC)-conjugated CD133/2 antibody (cat. no. 130-090-854; 1:10; clone 293C3; Miltenyi Biotec, Bergisch Gladbach, Germany) or fluorescein isothiocyanate (FITC)-conjugated CD34 antibody (cat. no. 130-081-001; 1:10; clone AC136; Miltenyi Biotec) for $30 \mathrm{~min}$ at $4^{\circ} \mathrm{C}$, and then washed twice with FACS buffer. Flow cytometry analysis was performed on an LSRII (BD Biosciences, San Jose, CA, USA), and forward light scatter and side scatter were recorded using 100,000 cells. Data were analyzed using FlowJo software (Tree Star Inc., Ashland, OR, USA).

Immunohistochemistry. IHC was performed as previously described, with a few modifications $(17,18)$. Briefly, tissue microarrays of human glioblastoma samples were deparaffinized and rehydrated, and then endogenous peroxidase activity was blocked with $3 \%$ hydrogen peroxide in methanol for $5 \mathrm{~min}$. Following incubation with a universal blocking buffer (2\% FBS in PBS) for 30 min to suppress nonspecific binding, the array slides were coated with primary antibodies [rabbit anti-CD133 (PROM1), 1:100, Abnova, Taipei, Taiwan; goat anti-CD45 (N-19), 1:100, Santa Cruz Biotechnology, Inc., Dallas, TX, USA; rabbit anti-vascular endothelial growth factor receptor 1 (VEGFR1; Y103), 1:25, Abcam, Cambridge, MA, USA; rabbit anti-VEGFR2 (EPRER16Y), 1:50, Abcam; rat anti-Notch1 (bTAN 20), 1:100, Abcam; mouse anti-integrin $\beta 4$ (58XB4), 1:100, Abcam; and rat anti-CD34 (QBEnd 10), 1:100, Dako, Glostrup, Denmark] for $1 \mathrm{~h}$ at room temperature. The detection system used was a Universal Dako Labelled Streptavidin-Biotin2 system, Horseradish Peroxidase (LSAB2 system, HRP) for CD133, VEGFR1, VEGFR2 and integrin $\beta 4$, and a VECTASTAIN Elite ABC kit for CD45, Notch1 and CD34.

All slides, except for CD34 [which used 3-amino-9-ethylcarbazole (product no. K346430; Dako) for $10 \mathrm{~min}$ ], were developed using 3,3'-diaminobenzidine (product no. S196730; Dako) for $10 \mathrm{~min}$, and each slide was counterstained with Mayer's hematoxylin for $15 \mathrm{sec}$. Staining intensity was quantified using the Aperio ImageScope (v12.0; Aperio Technologies, Vista, CA, USA) positive pixel count algorithm in 10 random fields $(250 \times 250 \mu \mathrm{m})$ from each slide (19). IHC 
Table I. Baseline information of the study populations.

A, Enhancement/necrosis group

\begin{tabular}{|c|c|c|c|c|c|c|}
\hline Case & Gender/age & $\begin{array}{l}\text { Extent of } \\
\text { resection }\end{array}$ & Pathology & $\begin{array}{l}\text { MGMT promoter } \\
\text { methylation }\end{array}$ & $\begin{array}{l}\text { IDH1 } \\
\text { mutation }\end{array}$ & $\begin{array}{c}\text { EGFR } \\
\text { amplification }\end{array}$ \\
\hline 1 & $\mathrm{~F} / 68$ & GTR & GBM (giant cell) & Unmethylated & Wild-type & No \\
\hline 2 & $\mathrm{M} / 59$ & GTR & GBM (gemistocytic astrocytes) & Methylated & Wild-type & No \\
\hline 3 & $\mathrm{M} / 45$ & GTR & GBM & Methylated & Wild-type & Yes \\
\hline 4 & $\mathrm{~F} / 67$ & NTR & GBM (small cell) & Methylated & Wild-type & No \\
\hline 5 & $\mathrm{~F} / 34$ & STR & GBM (oligodendroglial component) & Methylated & Mutation & No \\
\hline
\end{tabular}

B, Non-enhancement/infiltration group

\begin{tabular}{|c|c|c|c|c|c|c|}
\hline Case & Gender/age & $\begin{array}{l}\text { Extent of } \\
\text { resection }\end{array}$ & Pathology & $\begin{array}{l}\text { MGMT promoter } \\
\text { methylation }\end{array}$ & $\begin{array}{l}\text { IDH1 } \\
\text { mutation }\end{array}$ & $\begin{array}{c}\text { EGFR } \\
\text { amplification }\end{array}$ \\
\hline 6 & $\mathrm{~F} / 64$ & STR & GBM (small cell) & Methylated & Wild-type & Yes \\
\hline 7 & $\mathrm{M} / 43$ & NTR & GBM (gemistocytic astrocytes) & Methylated & Wild-type & No \\
\hline 8 & $\mathrm{~F} / 36$ & STR & GBM (oligodendroglial component) & Methylated & Mutation & No \\
\hline 9 & $\mathrm{M} / 42$ & GTR & GBM (oligodendroglial component) & Methylated & Mutation & No \\
\hline 10 & $\mathrm{M} / 46$ & GTR & GBM & Unmethylated & Wild-type & No \\
\hline
\end{tabular}

MGMT, O6-methylguanine-DNA methyltransferase; IDH1, isocitrate dehydrogenase 1; EGFR, epidermal growth factor receptor; GTR, gross total resection; NTR, near total resection; STR, subtotal resection; GBM, glioblastoma.

staining results were semiquantitatively graded as follows: no staining detected ( 0 , no positive tumor cells), faint staining (1+, $<10 \%$ positive tumor cells), moderate staining (2+, 10-50\% positive tumor cells), and strong staining $(3+,>50 \%$ positive tumor cells). In the case of the proliferation index assessed using antibody $\mathrm{Ki}-67$, positive staining was defined as $2+$ or $3+$ based on the percentage of tumor cells demonstrating immunoreactivity.

Microvessel density (MVD) was assessed as described previously (20). Briefly, the areas of highest neovascularization were selected, and single, or clusters of, endothelial cells that were positive for CD31 or CD34 were counted. A minimum of five histological fields were assessed to estimate the mean MVD for each case.

Imaging. Follow-up MRI scans of all patients were carried out using a 3-Tesla MR imaging scanner (Signa Excite, GE Medical Systems, Milwaukee, WI, USA; and Verio, Siemens Medical Solutions, Erlangen, Germany) with an eight-channel head coil. The imaging protocol included spin-echo (SE) T1-weighted images (T1WIs), fast SE (FSE) T2-weighted images (T2WIs), fluid-attenuated inversion recovery (FLAIR) images, echo-planar diffusion-weighted images, susceptibility-weighted images (SWIs), dynamic susceptibility contrast-enhanced perfusion-weighted images (DSC PWIs) with gadobutrol (Gadovist, Bayer Schering Pharma, Berlin, Germany), and subsequent contrast-enhanced (CE) SE T1WIs. The MRI parameters were as follows: 558-650/8-20 ms/70-90\%/384x192-212 [repetition time (TR)/echo time (TE)/flip angle (FA)/matrix] for SE
T1WIs; 4500-5160/91-106.3 ms/90-130\%/448-640x220 for FSE T2WIs; 9000-9900/97-162.9 ms/90-130\%199-220x220 for FLAIR images; and 28/20 ms/15/448x255 for SWIs. The other parameters included section thickness of $5 \mathrm{~mm}$ with a 1-mm gap and field of view (FOV) of 240x240 mm.

DSC PWI was performed with a single-shot gradient-echo echo-planar imaging sequence during intravenous injection of the contrast agent. The imaging parameters of DSC PWI were as follows: TR/TE, 1500/30-40 ms; FA, 35-90 FOV, 240x240 mm; 15-20 sections; matrix, 128x128; section thickness, $5 \mathrm{~mm}$; intersection gap, $1 \mathrm{~mm}$; and voxel resolution, 1.86x 1.86x $5 \mathrm{~mm}$. For each section, 60 images were obtained at intervals equal to the repetition time. After 4-5 time points, a bolus of gadobutrol, at a dose of $0.1 \mathrm{mmol} / \mathrm{kg}$ of body weight and a rate of $4 \mathrm{ml} /$ second, was injected with a MR-compatible power injector (Spectris; Medrad Inc., Pittsburgh, PA, USA). The bolus of the contrast material was followed by a $30-\mathrm{ml}$ bolus of saline, which was administered at the same injection rate.

Quantitative analysis of imaging values. The MRI data for the conventional MR images, the apparent diffusion coefficient (ADC) maps, and the DSC PWIs were digitally transferred from the picture archiving and communication system workstation to a personal computer for further analyses. Relative cerebral blood volumes (rCBVs) were obtained using a dedicated software package (nordicICE; NordicImagingLab, Bergen, Norway), with an established tracer kinetic model applied to first-pass data. First, realignment was performed to minimize patient motion during the dynamic scans. 
Table II. Distribution of tumor cell subpopulations expressing CD133 and CD34 in individual cases.

A, Enhancement/necrosis group

\begin{tabular}{|c|c|c|c|c|c|c|c|}
\hline \multirow[b]{2}{*}{ Case } & \multirow[b]{2}{*}{ Gender/age } & \multirow[b]{2}{*}{ Total CD133+ (\%) } & \multirow[b]{2}{*}{ Total CD $34^{+}(\%)$} & \multicolumn{2}{|c|}{$\mathrm{CD}_{133^{+}}$} & \multicolumn{2}{|c|}{$\mathrm{CD} 133^{-}$} \\
\hline & & & & $\mathrm{CD}^{3} 4^{+}(\%)$ & CD34- $(\%)$ & $\mathrm{CD}^{3} 4^{+}(\%)$ & CD34 $(\%)$ \\
\hline 1 & $\mathrm{~F} / 68$ & 0.09 & 1.40 & 1.12 & 98.88 & 0.95 & 99.05 \\
\hline 2 & $\mathrm{M} / 59$ & 0.62 & 7.36 & 12.32 & 87.68 & 7.17 & 92.83 \\
\hline 3 & $\mathrm{M} / 45$ & 0.16 & 16.78 & 14.37 & 85.63 & 12.25 & 87.75 \\
\hline 4 & $\mathrm{~F} / 67$ & 3.76 & 4.04 & 16.04 & 83.96 & 4.10 & 95.90 \\
\hline 5 & $\mathrm{~F} / 34$ & 5.95 & 1.08 & 16.67 & 83.33 & 0.89 & 99.11 \\
\hline
\end{tabular}

B, Non-enhancement/infiltration group

\begin{tabular}{|c|c|c|c|c|c|c|c|}
\hline \multirow[b]{2}{*}{ Case } & \multirow[b]{2}{*}{ Gender/age } & \multirow[b]{2}{*}{ Total CD133+ $(\%)$} & \multirow[b]{2}{*}{ Total CD34+ $(\%)$} & \multicolumn{2}{|c|}{$\mathrm{CD}_{133^{+}}$} & \multicolumn{2}{|c|}{$\mathrm{CD} 133^{-}$} \\
\hline & & & & $\mathrm{CD} 34^{+}(\%)$ & CD34- $(\%)$ & $\mathrm{CD} 4^{+}(\%)$ & $\mathrm{CD}^{-} 4^{-}(\%)$ \\
\hline 6 & F/64 & 0.28 & 8.82 & 22.00 & 78.00 & 9.07 & 90.93 \\
\hline 7 & $\mathrm{M} / 43$ & 0.12 & 1.38 & 22.06 & 77.94 & 1.19 & 98.81 \\
\hline 8 & $\mathrm{~F} / 36$ & 0.10 & 1.85 & 25.58 & 74.42 & 1.63 & 98.37 \\
\hline 9 & $\mathrm{M} / 42$ & 0.05 & 3.41 & 35.00 & 65.00 & 3.29 & 96.71 \\
\hline 10 & $\mathrm{M} / 46$ & 0.07 & 2.27 & 82.22 & 17.78 & 2.10 & 97.90 \\
\hline
\end{tabular}
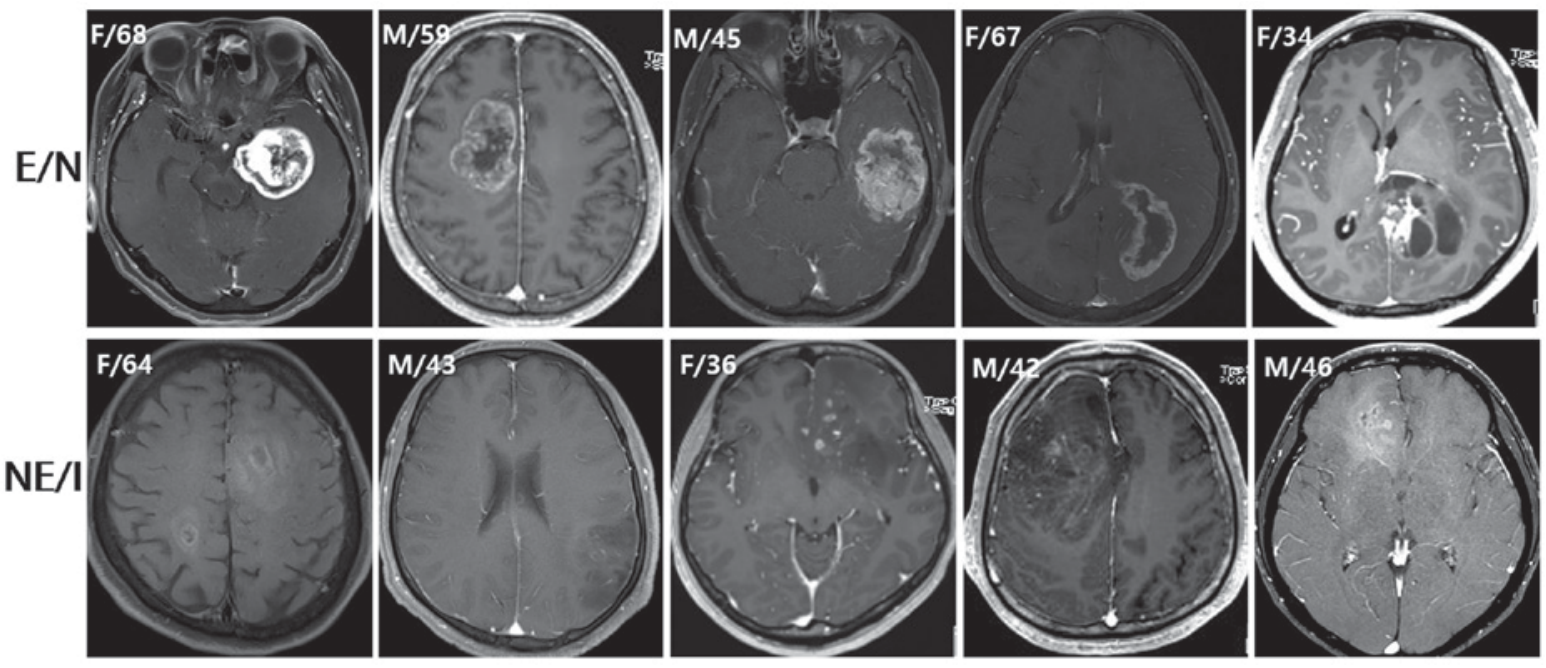

Figure 1. T1 contrast-enhanced magnetic resonance image characteristics of the study population. Ten newly diagnosed glioblastoma patients were classified into the enhancement/necrosis $(E / N, n=5)$ or non-enhancement/infiltration $(\mathrm{NE} / \mathrm{I}, \mathrm{n}=5)$ group based on contrast enhancement, necrosis and infiltrative pattern.

Gamma-variate function, which is an approximation of the first-pass response as it would appear in the absence of recirculation, was used to fit the $1 / \mathrm{T} 2 *(1 / \mathrm{T} 2+\gamma \Delta \mathrm{Binhom}$, where $\gamma$ is the gyromagnetic ratio) curves to reduce the effects of recirculation. To reduce contrast agent leakage effects, the dynamic curves were mathematically corrected (21). Following elimination of recirculation and of leakage of the contrast agent, the rCBV was computed by means of numeric integration of the curve. To minimize variances in the $\mathrm{rCBV}$ value in an individual patient, the pixel-based rCBV maps were normalized by dividing every $\mathrm{rCBV}$ value in a specific section by the rCBV value in the unaffected white matter, as defined by a neuroradiologist (22). Co-registrations between the CE T1WIs and the normalized CBV (nCBV) maps, and between the CE T1WIs and the ADC maps, were performed, based on geometric information stored in their respective data sets, using the dedicated software package nordicICE (22). The differences in slice thickness between the images were corrected automatically by the reslicing and co-registration method, which was based on the underlying and structural images. The $\mathrm{nCBV}$ and $\mathrm{ADC}$ maps were displayed as color overlays on the CE T1WIs. 
Table III. Angiogenesis-related protein expression.

\begin{tabular}{lcc}
\hline Gene & $\begin{array}{c}\text { Enhancement/ } \\
\text { necrosis group (\%) }\end{array}$ & $\begin{array}{c}\text { Non-enhancement/ } \\
\text { infiltration group (\%) }\end{array}$ \\
\hline CD45 & $2.2 \pm 1.7$ & $1.8 \pm 1.4$ \\
VEGFR1 & $3.8 \pm 1.3$ & $4.5 \pm 3.4$ \\
VEGFR2 & $3.3 \pm 3.1$ & $2.7 \pm 1.3$ \\
Notch1 & $0.2 \pm 0.1$ & $0.3 \pm 0.4$ \\
Integrin $\beta 4$ & $1.2 \pm 1.6$ & $1.1 \pm 0.6$ \\
\hline
\end{tabular}

The immunohistochemical result of the percentage of positively stained cells in each phenotype group is expressed as the mean \pm standard deviation. VEGFR, vascular endothelial growth factor receptor.

Table IV. Normalized cerebral blood volume histogram parameters of each phenotype group.

\begin{tabular}{lccc}
\hline Gene & $\begin{array}{c}\text { Enhancement/ } \\
\text { necrosis } \\
\text { group (\%) }\end{array}$ & $\begin{array}{c}\text { Non-enhancement/ } \\
\text { infiltration } \\
\text { group (\%) }\end{array}$ & P-value \\
\hline Mean & $2.4 \pm 0.9$ & $2.0 \pm 0.8$ & 0.535 \\
Mode & $1.8 \pm 0.9$ & $2.8 \pm 0.7$ & 0.921 \\
Kurtosis & $2.8 \pm 1.3$ & $1.9 \pm 1.4$ & 0.365 \\
Skewness & $1.5 \pm 0.4$ & $1.0 \pm 0.4$ & 0.048 \\
\hline
\end{tabular}

Data are presented as means \pm standard deviations.

Using histograms of the $\mathrm{nCBV}$ and ADC maps, we obtained the mean, mode, skewness and kurtosis for comparison.

Statistical analysis. All statistical analyses were carried out using IBM SPSS statistical software version 21 (IBM SPSS, Armonk, NY, USA). The Mann-Whitney U test was used to compare two groups of observations, and the Kendall tau to calculate the correlation coefficient. All analyses were two-sided, and $\mathrm{P}<0.1$ was considered to indicate a statistically significant difference.

\section{Results}

Higher $\mathrm{CD}_{34^{+}}$cell fraction in $\mathrm{CD}_{133^{+}}$cells in NE/I glioblastomas. Tumor cell populations expressing CD133 and CD34 were measured by tissue FACS. The subpopulation fraction results for individual cases are presented in Table II. The median fraction of $\mathrm{CD}_{133^{+}}$cells represented $0.16 \%$ (range, $0.05-5.95 \%$ ) of the total tumor cell population per case. The $\mathrm{CD}_{133}{ }^{+}$cell fraction was higher in the $\mathrm{E} / \mathrm{N}$ group than in the NE/I group (Fig. 2A; median $0.62 \%$ vs. $0.07 \%$, respectively; $\mathrm{P}=0.076)$. However, there was no difference in the $\mathrm{CD} 34^{+}$cell fraction between the two groups (Fig. 2B; median $4.04 \%$ vs. $3.41 \%$, respectively; $\mathrm{P}=0.754$ ). The median fraction of $\mathrm{CD} 34^{+}$ cells in the total tumor cell population per case was $3.41 \%$ (range, 1.08-16.78\%). However, the percentage expressing $\mathrm{CD}^{+}{ }^{+}$in the $\mathrm{CD} 133^{+}$cell fraction (EPC fraction in CSCs,

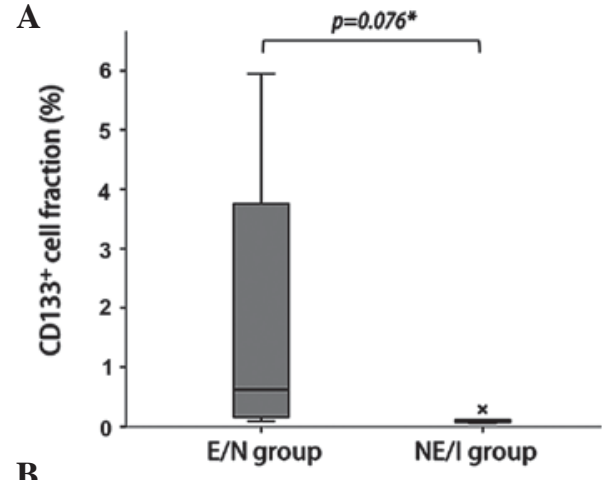

B
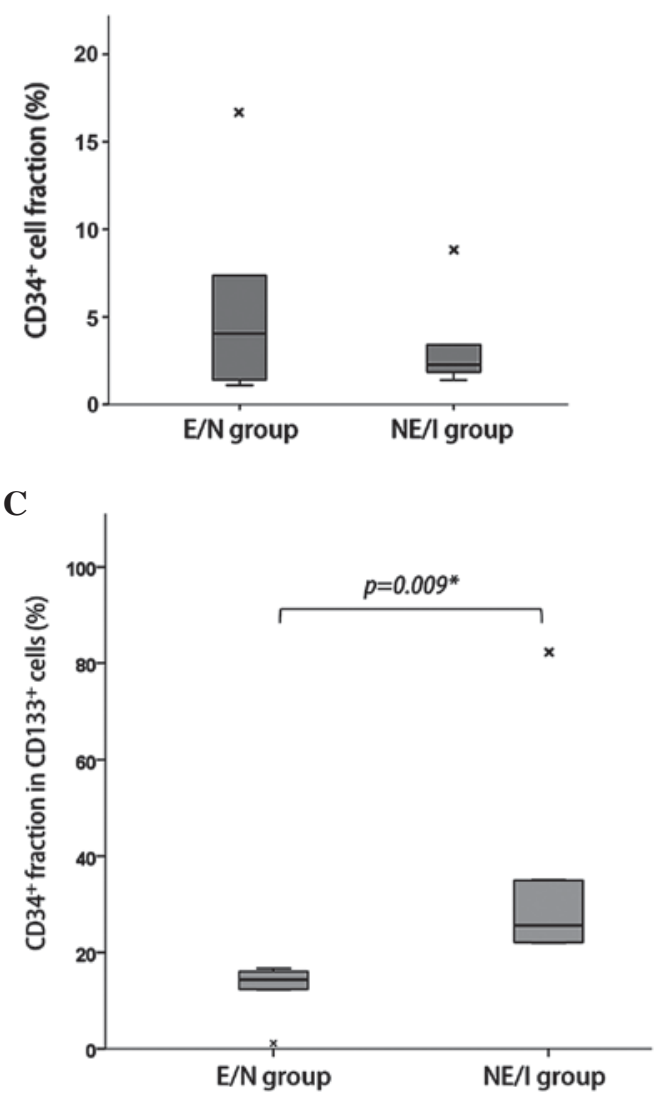

Figure 2.Fractions of cells expressing CD133 and CD34 in tumor tissue assessed by fluorescence-activated cell sorting. (A) A higher CD133+ cell fraction was detected in the enhancement/necrosis $(\mathrm{E} / \mathrm{N})$ group than in the non-enhancement/infiltration $(\mathrm{NE} / \mathrm{I})$ group (median $0.62 \%$ vs. $0.07 \%, \mathrm{P}=0.076$ ). (B) No statistically significant differences were detected in the CD34+ cell fraction between the $\mathrm{E} / \mathrm{N}$ group and NE/I group (median $4.04 \%$ vs. $3.41 \%$, $\mathrm{P}=0.754)$. (C) A significantly higher percentage of $\mathrm{CD} 34^{+} / \mathrm{CD} 133^{+}$cells was detected in the NE/I group than the $\mathrm{E} / \mathrm{N}$ group $(25.58 \%$ vs. $14.37 \%, \mathrm{P}=0.009)$. ${ }^{*} \mathrm{P}<0.01$. $\mathrm{x}$ represents an outlying data point.

$\mathrm{CD} 4^{+} / \mathrm{CD} 133^{+}$) was significantly higher in the NE/I group than the E/N group (Fig. 2C; $25.58 \%$ vs. $14.37 \%$, respectively; $\mathrm{P}=0.009)$. On the other hand, the percentage expressing CD34 cells in the $\mathrm{CD}_{133^{+}}$cell fraction (non-EPC fraction in CSCs, $\mathrm{CD} 34^{-/ C D} 133^{+}$) was significantly higher in the $\mathrm{E} / \mathrm{N}$ group than the NE/I group (87.90\% vs. $62.63 \%$, respectively; $\mathrm{P}=0.008)$.

Angiogenesis is phenotype-independent in glioblastomas. Double-staining IHC for CD133 and CD34 identified the perivascular localization of the $\mathrm{CD} 34^{+} / \mathrm{CD} 133^{+}$cells (Fig. 3A). However, there was no statistical difference in MVD between 


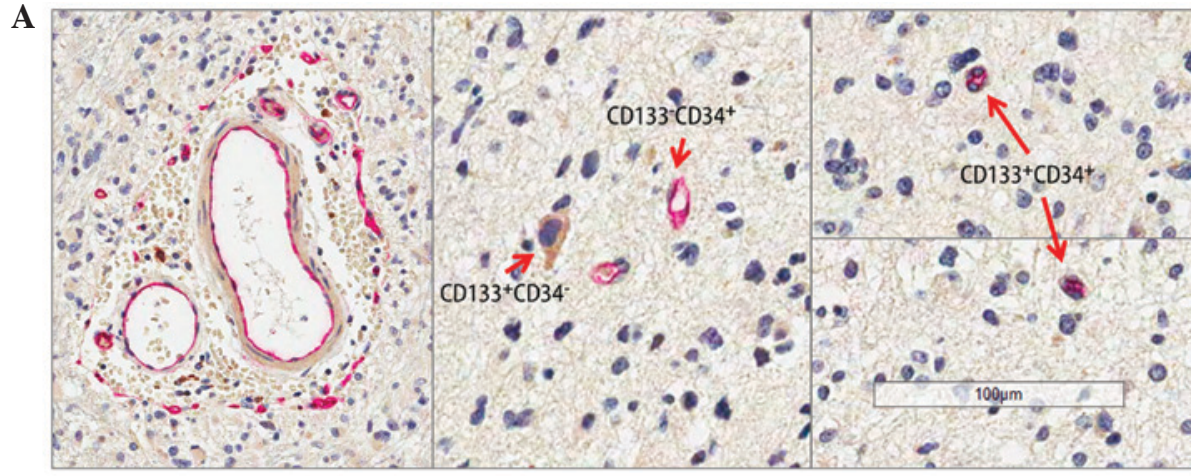

B
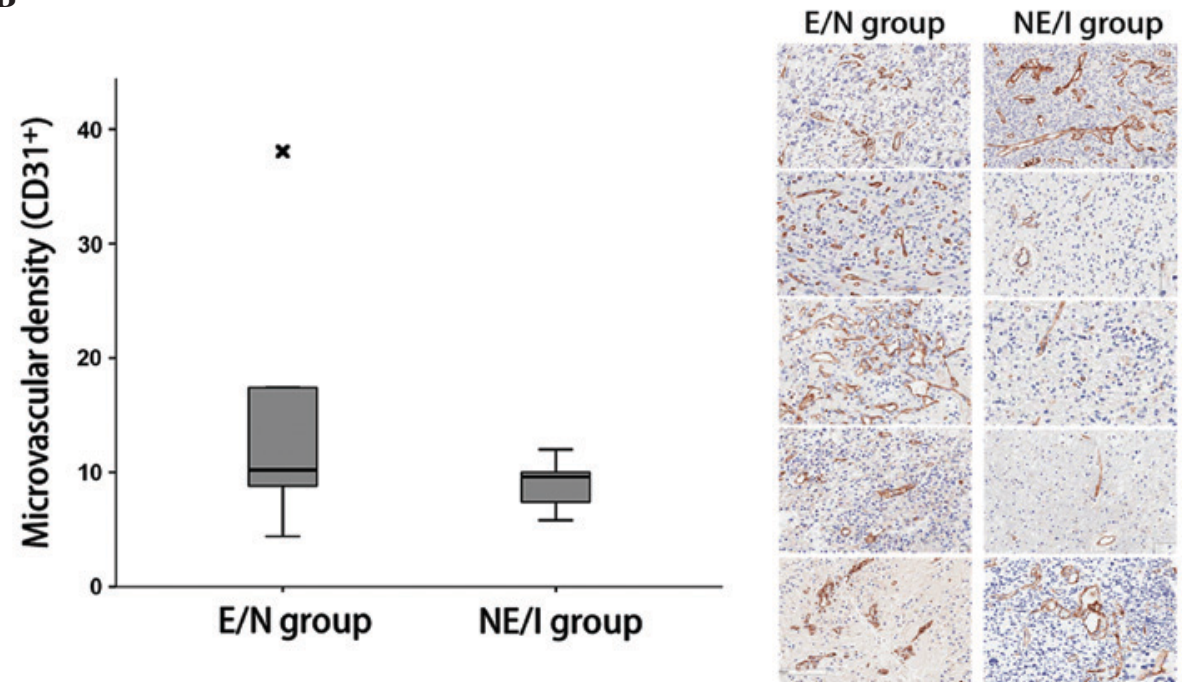

Figure 3. (A) Double immunohistochemical staining of CD133 (brown) and CD34 (red) protein expression in glioblastoma tissue. Note the perivascular localization of $\mathrm{CD}_{133^{+}}$and $\mathrm{CD} 34^{+}$cells. (B) Microvascular density indicates no statistical differences in angiogenesis features between the enhancement/necrosis $(\mathrm{E} / \mathrm{N})$ group and the non-enhancement/infiltration (NE/I) group. The blood vessels were immunohistochemically stained with anti-CD31 antibody. $\mathrm{x}$ represents an outlying data point.

A

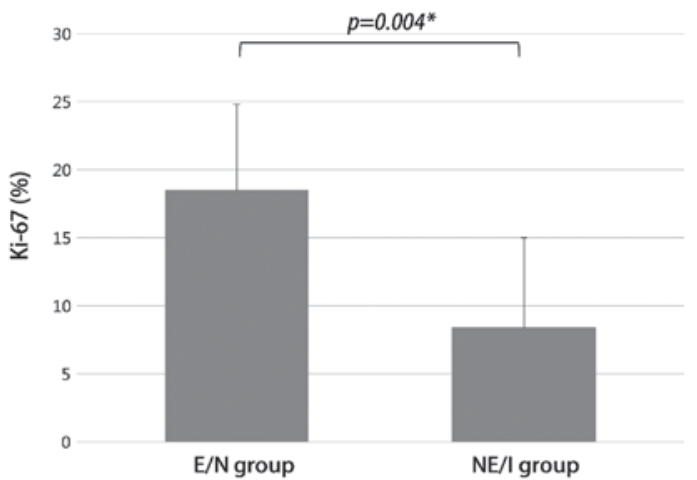

B

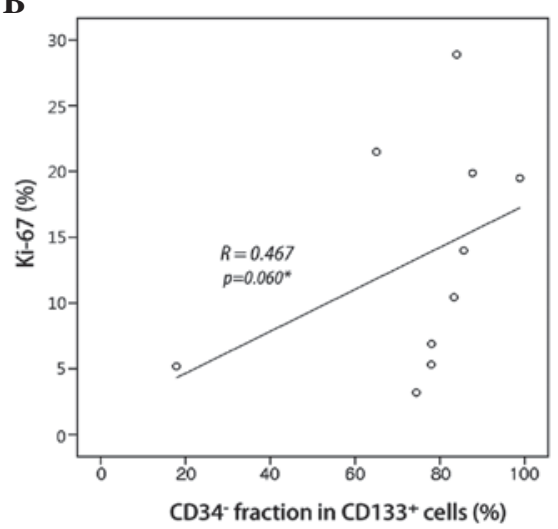

Figure 4. Detection of proliferating cells in the glioblastomas. (A) A significantly higher proliferation index measured by Ki-67 was present in the enhancement/necrosis $(\mathrm{E} / \mathrm{N})$ group compared with the non-enhancement/infiltration (NE/I) group (18.5 $\pm 6.3 \%$ vs. $8.4 \pm 6.6 \%, \mathrm{P}=0.004)$. (B) Ki-67 was positively correlated with the $\mathrm{CD} 34 / \mathrm{CD} 133^{+}$fraction in glioblastoma tissues $(\mathrm{R}=0.467, \mathrm{P}=0.060)$.

the E/N and NE/I groups (Fig. 3B). There was also no difference in protein expression related to angiogenesis between the two groups (Table III).

Histogram analysis for perfusion MRI is summarized in Table IV. When comparing the histogram parameters between the E/N and NE/I groups, only the skewness of $\mathrm{nCBV}$ was significantly different $(\mathrm{P}=0.048)$. There were no differences in other perfusion MRI parameters between the two groups.

Higher proliferative potential in E/N glioblastomas correlates with $C D 34^{-} / C D 133^{+}$cell fraction. Proliferation index measurement, using Ki-67 IHC, revealed a significant increase in the E/N group, compared with the NE/I group (Fig. 4A; 
$18.5 \pm 6.3 \%$ vs. $8.4 \pm 6.6 \% ; \mathrm{P}=0.004)$. As the $\mathrm{E} / \mathrm{N}$ group had a larger $\mathrm{CD} 34^{-} / \mathrm{CD} 133^{+}$cell fraction than the NE/I group, we examined the correlation between CD34/CD133+ cell fractions and $\mathrm{Ki}-67$ in whole-study samples. A positive correlation was observed between $\mathrm{CD} 34^{-} / \mathrm{CD} 133^{+}$cell fractions and $\mathrm{Ki}-67$ (Fig. 4B; $R=0.467, \mathrm{P}=0.060$ ). This result indicates that a larger $\mathrm{CD} 34 \% \mathrm{CD} 133^{+}$cell fraction correlates with a greater cellular proliferation and is associated with the $\mathrm{E} / \mathrm{N}$ radiographic phenotype.

\section{Discussion}

We have previously demonstrated that there is a distinct subpopulation of $\mathrm{CD} 133^{+}$cells in human brain tumors, with characteristics of EPCs $\left(\mathrm{CD} 34^{+} / \mathrm{CD} 33^{+}\right)$(9). The functional role of EPCs in oncogenesis has been identified as that of increased angiogenic potential, which is an essential element for tumor progression (9). EPCs are known to be recruited to sites of neovascularization from the bone marrow, or to be transdifferentiated from CSCs (12,23-26). In addition, we observed various EPC fractions in CSCs among different cancer types (9). This led to the speculation of a possible correlation between EPC fractions and phenotypic characteristics associated with angiogenesis in specific tumors. Glioblastoma is the ideal tissue material to test this hypothesis, as it harbors heterogeneous imaging characteristics, thus implying a diverse degree of angiogenesis, necrosis and proliferation. Furthermore, it has also been studied extensively using advanced imaging techniques, thus providing us with sufficient cumulative knowledge for the imaging characteristics to be interpreted. Therefore, we defined two phenotypically distinct groups of glioblastoma, based on their MRI characteristics, which we then used to test the hypothesis. We consider that the $\mathrm{E} / \mathrm{N}$ group is representative of angiogenesis-prone cases while the NE/I group represents cases with lower angiogenic potential.

Against our expectations, there was no evidence of differences in angiogenic activity between the two groups assessed by MVD. Moreover, the EPC fraction $\left(\mathrm{CD}_{3} 4^{+} / \mathrm{CD} 33^{+}\right)$in CSCs was higher in the NE/I group whereas the $\mathrm{CD} 34^{-} / \mathrm{CD} 133^{+}$cell fraction in the $\mathrm{CD} 133^{+}$cell population was significantly higher in the $\mathrm{E} / \mathrm{N}$ group, compared with the NE/I group. This implies that angiogenic potential is not a major factor associated with radiographic phenotypic changes. There were also no differences in the perfusion MRI parameters, thus supporting the microscopic IHC evidence. This is in line with the findings of a previous study on glioblastoma, which revealed that there was histopathologically no difference in overall and simple vascular hyperplasia between samples from $\mathrm{T} 1$ contrast enhancement areas and samples from non-contrast areas (27). This study further demonstrated that delicate microvascular hyperplasia is more frequently observed in specimens from non-enhancement areas (27). Another previous study on the use of anti-angiogenic therapy for glioblastoma revealed that the significant reduction in contrast enhancement following anti-angiogenic treatment was not due to the decrease in MVD (28). The authors concluded that contrast enhancement does not accurately reflect vascular density (28). However, there are still conflicting views on the role of perfusion MRI for predicting MVD (29).
In our previous study, we confirmed that the CD34/CD133+ subpopulation comprised the oncogenic cells that led to tumors in vivo (9). In the same study, we also revealed the $\mathrm{CD} 4^{-} / \mathrm{CD} 133^{+}$cell fraction to be the major component for proliferation in tumor models (9). Results from the present study indicate that the $\mathrm{CD} 344^{-/ \mathrm{CD}} 133^{+}$fraction in the $\mathrm{CD} 133^{+}$ cell population is higher in the $\mathrm{E} / \mathrm{N}$ group compared with the NE/I group, and this correlated with the proliferation index. Therefore, this finding provides further support for the proliferative potential of the $\mathrm{CD} 34^{-} / \mathrm{CD} 133^{+}$cell fraction in human glioblastoma samples. Moreover, we established an association between this subpopulation of CSCs and the radiographic characteristics of the tumors. Studies investigating MRI characteristics in the early phase of glioblastoma evolution have reported that ill-defined hyperintense areas on T2WIs without contrast enhancement represent the incipient stage of cancer $(30,31)$. Furthermore, a higher proliferative index in contrast-enhanced areas was documented by another research group (27).

The EPC fraction in CSCs was increased in glioblastomas without contrast enhancement on MRI. However, angiogenesis was not a major factor influencing radiographic characteristics. Our study suggests that the non-EPC fractions in CSCs are associated with oncogenic proliferation and are responsible for radiographic changes in glioblastomas. Therefore, as a surrogate marker of proliferation potential, the simple non-invasive assessment method of contrast enhancement lesions in glioblastoma could be used to estimate CSC subpopulations or to guide in the selection of therapeutic agents targeting CSCs. The limitation of this study is the lax statistical standard, and the small number of samples, which prohibits parametric tests between groups. Larger study samples are required to validate the results in the future.

Simple non-invasive assessment of contrast enhancement lesions for glioblastoma may be utilized to provide a biomarker for estimating the presence of subpopulations of CSCs.

\section{Acknowledgements}

This study was supported by grants from the Korea Health Technology R\&D Project, Ministry of Health and Welfare, Republic of Korea (A120446), and the Seoul National University Hospital Research Fund (03-2012-0130).

\section{References}

1. Singh SK, Clarke ID, Hide T and Dirks PB: Cancer stem cells in nervous system tumors. Oncogene 23: 7267-7273, 2004.

2. Singh SK, Hawkins C, Clarke ID, Squire JA, Bayani J, Hide T, Henkelman RM, Cusimano MD and Dirks PB: Identification of human brain tumour initiating cells. Nature 432: 396-401, 2004.

3. Bidlingmaier S, Zhu X and Liu B: The utility and limitations of glycosylated human CD133 epitopes in defining cancer stem cells. J Mol Med (Berl) 86: 1025-1032, 2008.

4. Joo KM, Kim SY, Jin X, Song SY, Kong DS, Lee JI, Jeon JW, Kim MH, Kang BG, Jung Y, et al: Clinical and biological implications of CD133-positive and CD133-negative cells in glioblastomas. Lab Invest 88: 808-815, 2008.

5. Beier D, Hau P, Proescholdt M, Lohmeier A, Wischhusen J, Oefner PJ, Aigner L, Brawanski A, Bogdahn U and Beier CP: CD133(+) and CD133(-) glioblastoma-derived cancer stem cells show differential growth characteristics and molecular profiles. Cancer Res 67: 4010-4015, 2007. 
6. Ogden AT, Waziri AE, Lochhead RA, Fusco D, Lopez K, Ellis JA, Kang J, Assanah M, McKhann GM, Sisti MB, et al: Identification of A2B5+CD133- tumor-initiating cells in adult human gliomas. Neurosurgery 62: 505-514; discussion 514-515, 2008.

7. Wang J, Sakariassen PØ, Tsinkalovsky O, Immervoll H, Bøe SO, Svendsen A, Prestegarden L, Røsland G, Thorsen F, Stuhr L, et al: CD133 negative glioma cells form tumors in nude rats and give rise to CD133 positive cells. Int J Cancer 122: 761-768, 2008.

8. Christensen K, Aaberg-Jessen C, Andersen C, Goplen D, Bjerkvig R and Kristensen BW: Immunohistochemical expression of stem cell, endothelial cell, and chemosensitivity markers in primary glioma spheroids cultured in serum-containing and serum-free medium. Neurosurgery 66: 933-947, 2010.

9. Choi SA, Wang KC, Phi JH, Lee JY, Park CK, Park SH and Kim SK: A distinct subpopulation within CD133 positive brain tumor cells shares characteristics with endothelial progenitor cells. Cancer Lett 324: 221-230, 2012.

10. Ribatti D: The involvement of endothelial progenitor cells in tumor angiogenesis. J Cell Mol Med 8: 294-300, 2004.

11. Ricci-Vitiani L, Pallini R, Biffoni M, Todaro M, Invernici G, Cenci T, Maira G, Parati EA, Stassi G, Larocca LM and De Maria R: Tumour vascularization via endothelial differentiation of glioblastoma stem-like cells. Nature 468: 824-828, 2010.

12. Wang R, Chadalavada K, Wilshire J, Kowalik U, Hovinga KE, Geber A, Fligelman B, Leversha M, Brennan C and Tabar V: Glioblastoma stem-like cells give rise to tumour endothelium. Nature 468: 829-833, 2010.

13. Diehn M, Nardini C, Wang DS, McGovern S, Jayaraman M, Liang Y, Aldape K, Cha S and Kuo MD: Identification of noninvasive imaging surrogates for brain tumor gene-expression modules. Proc Natl Acad Sci USA 105: 5213-5218, 2008.

14. Aghi M, Gaviani P, Henson JW, Batchelor TT, Louis DN and Barker FG II: Magnetic resonance imaging characteristics predict epidermal growth factor receptor amplification status in glioblastoma. Clin Cancer Res 11: 8600-8605, 2005.

15. Tykocinski ES, Grant RA, Kapoor GS, Krejza J, Bohman LE, Gocke TA, Chawla S, Halpern CH, Lopinto J, Melhem ER and O'Rourke DM: Use of magnetic perfusion-weighted imaging to determine epidermal growth factor receptor variant III expression in glioblastoma. Neuro Oncol 14: 613-623, 2012.

16. Butts CL and Sternberg EM: Flow cytometry as a tool for measurement of steroid hormone receptor protein expression in leukocytes. Methods Mol Biol 505: 35-50, 2009.

17. Liu X, Zhou B, Xue L, Shih J, Tye K, Lin W, Qi C, Chu P, Un F, Wen W and Yen Y: Metastasis-suppressing potential of ribonucleotide reductase small subunit p53R2 in human cancer cells. Clin Cancer Res 12: 6337-6344, 2006.

18. Simon R, Mirlacher M and Sauter G: Immunohistochemical analysis of tissue microarrays. Methods Mol Biol 664: 113-126, 2010.

19. Pio R, Jia Z, Baron VT and Mercola D; UCI NCI SPECS Consortium of the Strategic Partners for the Evaluation of Cancer Signatures-Prostate Cancer: Early growth response 3 (Egr3) is highly over-expressed in non-relapsing prostate cancer but not in relapsing prostate cancer. PLoS One 8: e54096, 2013.
20. Weidner N, Semple JP, Welch WR and Folkman J: Tumor angiogenesis and metastasis-correlation in invasive breast carcinoma. N Engl J Med 324: 1-8, 1991.

21. Boxerman JL, Schmainda KM and Weisskoff RM: Relative cerebral blood volume maps corrected for contrast agent extravasation significantly correlate with glioma tumor grade, whereas uncorrected maps do not. AJNR Am J Neuroradiol 27: 859-867, 2006

22. Wetzel SG, Cha S, Johnson G, Lee P, Law M, Kasow DL, Pierce SD and Xue X: Relative cerebral blood volume measurements in intracranial mass lesions: interobserver and intraobserver reproducibility study. Radiology 224: 797-803, 2002.

23. Mohle R, Bautz F, Rafii S, Moore MA, Brugger W and Kanz L: The chemokine receptor CXCR-4 is expressed on CD34+ hematopoietic progenitors and leukemic cells and mediates transendothelial migration induced by stromal cell-derived factor-1. Blood 91: 4523-4530, 1998.

24. Scully S, Francescone R, Faibish M, Bentley B, Taylor SL, Oh D, Schapiro R, Moral L, Yan W and Shao R: Transdifferentiation of glioblastoma stem-like cells into mural cells drives vasculogenic mimicry in glioblastomas. J Neurosci 32: 12950-12960, 2012

25. Soda Y, Marumoto T, Friedmann-Morvinski D, Soda M, Liu F, Michiue H, Pastorino S, Yang M, Hoffman RM, Kesari S and Verma IM: Transdifferentiation of glioblastoma cells into vascular endothelial cells. Proc Natl Acad Sci USA 108: 4274-4280, 2011.

26. Patenaude A, Parker J and Karsan A: Involvement of endothelial progenitor cells in tumor vascularization. Microvasc Res 79: 217-223, 2010.

27. Barajas RF Jr, Phillips JJ, Parvataneni R, Molinaro A, Essock-Burns E, Bourne G, Parsa AT, Aghi MK, McDermott MW, Berger MS, et al: Regional variation in histopathologic features of tumor specimens from treatment-naive glioblastoma correlates with anatomic and physiologic MR imaging. Neuro Oncol 14: 942-954, 2012.

28. Jalali S, Chung C, Foltz W, Burrell K, Singh S, Hill R and Zadeh G: MRI biomarkers identify the differential response of glioblastoma multiforme to anti-angiogenic therapy. Neuro Oncol 16: 868-879, 2014.

29. Sadeghi N, D'Haene N, Decaestecker C, Levivier M, Metens T, Maris C, Wikler D, Baleriaux D, Salmon I and Goldman S: Apparent diffusion coefficient and cerebral blood volume in brain gliomas: relation to tumor cell density and tumor microvessel density based on stereotactic biopsies. AJNR Am J Neuroradiol 29: 476-482, 2008.

30. Okamoto K, Ito J, Takahashi N, Ishikawa K, Furusawa T, Tokiguchi S and Sakai K: MRI of high-grade astrocytic tumors: early appearance and evolution. Neuroradiology 44: 395-402, 2002.

31. Nishi N, Kawai S, Yonezawa T, Fujimoto K and Masui K: Early appearance of high grade glioma on magnetic resonance imaging. Neurol Med Chir (Tokyo) 49: 8-12, 2009. 